\title{
Dansinkran Hairstyle Fashion and Its Socio-Cultural Significance in Akan Traditional Ruling
}

\author{
Kennedy Asenso \\ S.D.A. College of Education, Asokore-Koforidua
}

\begin{abstract}
The value of hair to women seems to be succinctly expressed in the words of Martin Luther that 'hair is the richest ornament of women'. For many women of African descent, hair is emotive, symbolic and an inseparable part of our identity. The objective of the study was to examine socio-cultural significance of Dansinkran in Akan traditional ruling. For this study, the researcher used personal interviews with some Akan Queen mothers on their Dansinkran hair styles and utilized qualitative research methods, with heavy emphasis on literature review. The researcher employed a case study design in the research. The study unravelled that; Dansinkran hair style enhances thinking capacity of the Akan Queen mothers as they used charcoal, it detoxify every chemical in the hair and allow the brain to function with its full capacity. The researcher recommends that in writing of our country history as a means to preserve and conserve it, the inclusion of history of hairdressing would make it richer and also add to the existing repository of knowledge.
\end{abstract}

Keywords: Dansinkran, Culture, Hairstyles, Identity, Symbolic.

DOI: $10.7176 / \mathrm{JCSD} / 49-05$

Publication date: June $30^{\text {th }} 2019$

\subsection{Introduction}

The practice of hair shaving among both men and women has been a culturally specific practice. Bell (2008) put forward that, Hair is one of most important aspects of beauty culture, particularly within the Black community. In many cultures, hair is what determines a woman's beauty. However, historically, "black people's hair, especially that of black women, became a site for complex social and cultural politics that questioned traditional concepts of beauty and blackness."

According to Weitz, (2004) hair is a social construct that is deeply connected to the identities of women, and she describes hair as "Part of a broader language of appearance, which, whether or not we intend it, tells others about ourselves". Symbols existing within this phenomenon that makes up a broader language is communicated to those we meet to make statements about who we are. This can be done both purposefully and unintentionally as people often misread the intended meanings of these symbols. Hair is central to the establishment and maintenance of individual and group identity.

According to historian Russell and Adams (1978), no one knows when humans first engaged in the practice of hair removal. Rudimentary attempts at shaving can be traced back to prehistoric cave drawings in which depictions of men appeared without beards or other facial hair. But the basic technology of the time meant that shaving likely involved using a flint axe or sharpened animal teeth on the face, a dangerous operation. Upon the invention of a more sophisticated flint razor, Egyptian males were known to have shaved both their faces and their heads. The reason was a practical one, according to Adams; in a combat situation a smooth head and face deprived the enemy of a handhold grip with which to behead his victim. With this description in mind, Adams explains, we can rule out any explanations of vanity or beauty, especially since older civilizations lacked devices like mirrors for self-scrutiny.

Other civilizations engaged in the practice of facial shaving for ostensibly the same reason. Alexander the Great is said to have removed his beard and ordered his soldiers to do the same in order to avoid decapitation in battle. Although beards originally symbolized manhood and health in early Roman culture, the Romans were soon following the trend of Alexander the Great and other Greeks, removing their beards in the event of war. A cleanshaven man thus became the symbol of civilization and progress, while a bearded man became the symbol of slavery, servitude and barbarism throughout the Roman Empire.

A Cultural Historian, Victoria Sherrow (2006) provides evidence that women in ancient Egypt, Greece and the Roman Empire removed all the hair from their bodies. In ancient Egypt women used beeswax or cream depilatories composed of an alkali to remove the hair from their legs. Women in ancient Egypt also removed pubic hair, as did Greek women, because, according to Sherrow, they believed the presence of such hair was "uncivilized.' So distasteful was the presence of body hair on women in ancient Greece, that Greek artists molded their statues of women without pubic hair.

The aversion to pubic hair was not restricted to ancient Egypt and Greece; in other Middle Eastern countries such as Turkey, Palestine and Lebanon, brides were expected to remove all body hair, with the exception of eyebrows and head hair, on the eve of the wedding ceremony. In some central African tribes, brides plucked their pubic hair, or removed it through a rudimentary form of shaving. 
Johnson, and Bankhead, (2014) discussed that, Who I am and how I feel about who I am, are essential questions that help define and construct identity. For Black women and girls, identity is inextricably linked to their relationship to and presentation of their hair. Hair is important in many cultures and its meaning and symbolism vary depending on social and cultural context. For African people, hair is deeply symbolic, and its meaning extends into multiple dimensions of Black culture and life. This meaning is both deep and wide; in other words, hair may have spiritual and religious connotations. It may play an essential socio-cultural role and at other times its meaning may serve as a method of self-expression.

Bell (2008) posit that, Since Black women face such high pressures to alter their appearance, they are putting their health at risk for the chance to fulfil an unattainable beauty standard. Why are Black women altering their natural hair texture with unnatural and toxic products such as hair relaxers? It is because "hair is something that can be seen and read immediately, especially if it does not meet mainstream standards.

Russell-Cole, Wilson, and Hall,(2013) postulated that, Since 1808, Black women have been altering the natural textures of their hair to fit dominant European standards. Acculturation has concealed the natural hair style of blacks people especially the Akans of Ghana, as the pressures to have arguably 'good' hair, or hair that is straighter and easier to manage is already present.

Byrd \& Tharps (2001) hypothesized that, In the Black community, hair has been defined as either "good" or "bad" hair: " 'good' hair meaning that the hair looks 'European' straight, and 'bad' hair as 'woolly' or 'tough' hair. The pressure to either convert 'bad' hair into "good" hair, or vice versa, to convert "good" hair into "bad" hair to avoid being teased by others is very strong for young Black children, especially, young black girls. Against all this acculturation background, Akans Queen mothers have been able to maintain their Dansinkran hair style as a means to preserve and conserved their cultural identity.

\subsection{Problem Statement.}

Since time immemorial, different hairstyle had come over and over again, but Akan Dansinkran hair style has remained peculiar to the Akan Queen mothers of Ghana and has remained unchanged for centuries. The study is geared towards finding the socio-cultural significance of the Dansinkran hairstyle among Akans queen mothers in Ghana.

\subsection{Purpose of the Study}

The purpose of the study is geared towards finding socio-cultural significance of Dansinkran in Akan traditional ruling in Ghana.

\subsection{Objective}

$>$ Examine socio-cultural significance of Dansinkran in Akan traditional ruling.

\subsection{Research Question}

* What is the socio-cultural significance of Dansinkran in Akan traditional ruling.

\section{Review of Literature \\ 2.0 Introduction}

This chapter reviews the topic on empirical literature on the following related thematic areas:

$>$ Indigenous hair-styling culture of Ghanaian women

$>$ Akan hair-styling techniques and etiquette

$>$ Dansinkran hairstyle of Akan queen mothers

\subsection{Indigenous Hair-Styling Culture Of Ghanaian Women}

According to Trüeb (2006), hair constitutes an important part of the overall appearance of a person. The same face can make different impressions as the hairstyle of a person is varied, because human scalp hair frames the face.

Rosemary ( 1964), postulated that, Hair styles are uniquely distinctive, autonomous, self-contained, unified, exclusive of the extraneous and complete in themselves because they occur in the context of people, human life and culture, ideas and history. A study by Mercer (1987) showed that hair on the scalp has significant bearing on the Self-image of an individual. The condition and style of scalp hair influences the perception of others about the wearers because hair is one of the few characteristics that are manipulated in length, colour and style (Bolduc \& Shapiro, 2001). Hair also serves as a medium through which significant statements about 'self' and society and the codes of values that bind them and others are made (Mercer, 1987).

According to Puke and Shaibu (2001), Culture, is a whole body of knowledge, beliefs, arts, laws, norms, customs, values, habits and other capabilities acquired by country (Ghana), or a group of people as members of their society. In essence, Ghanaian cultural heritage as a result is an embodiment of values and meanings constructed by cultural group or societies with high standards of originality as posited by (Puke and Shaibu 2001, 
56-58). It is a cultural heritage that derives from Black culture which, according to Senghor, is a set of values originating from an original to blacks that is expressed in their different national cultures. Whether ancient or contemporary, in West Africa political institutions, traditions of moral values, languages, literature, and the fine arts all derive from Black culture. The culture of a people is so strong that it is expressed even in the way the people walk, laugh or cry (Senghor 1977, 80- 82). This deep embodiment of culture is embedded into hair styles in Ghana. Historically, various symbolic hairstyles were designated for special causes and for special classes of people in society, as situated in time past in Ghana. Oziogu describes a symbolic hair style designated for spinsters, unmarried women, elderly women, women who have passed child- bearing age, and childless women.

According to Roseborough and McMicheal (2009), women commit considerable time and expense to daily hair grooming, both at home and the hair salons, for special occasions and everyday appearances. This tradition of women could be explainable by the fact that beautiful and healthy scalp hair generally expresses femininity irrespective of culture of the individual (Aboagye, 2011). The value of hair to women seems to be succinctly expressed in the words of Martin Luther that 'hair is the richest ornament of women'. For many women of African descent, hair is emotive, symbolic and an inseparable part of their identity.

DeGruy (2000) postulated the consequence Africans have had as a result of long history of using drastic measures to attain "desirable" hair. Straightening highly textured African hair often requires the use of toxic chemicals or heat intensive tools such as a straightening comb or flat iron, which may be heated to over 400 degrees. Hair relaxers are used by millions of Black women and expose them to various chemicals through scalp lesions and burns. In addi- tion, harmful chemicals cause minor to severe hair loss including balding, burns, and color change. DeGruy (2000) noted that chemicals used in hair relaxers caused injury in the mouth and esophagus when ingested and such products must therefore be labelled poisonous. Wise et al. tested hair relaxer use in relation to uterine leiomyomata (fibroids) incidence among premenopausal Black women. Women who used chemical relaxers had higher incidents of uterine fibroids than those who never used relaxers. More precisely, 7146 cases of uterine leiomyomata were reported as confirmed by ultrasound $(\mathrm{n}=4630)$ or surgery $(\mathrm{n}=2516)$. The incidence rate ratio comparing ever with never use of relaxers was 1.17 (95\% confidence interval $(\mathrm{CI}): 1.06,1.30)$. The findings indicate that hair relaxer use increases uterine leiomyomata (fibroid) risk. There are clearly dire risks involved with continuing the use of chemical relaxers that often require application every $6-8$ weeks after the new hair grows.

\subsection{Akan Hair-Styling Techniques And Etiquette}

The Akan occupy about Nine (9) of the current Sixteen (16) regions of Ghana namely: Eastern Region, Ashanti, Central, Western, Bono region, Bono East. Ahafo, Western North, and Oti region.

According to Ghana Statistical Service (2013:61) report, Akan is the largest ethnic group in Ghana, making up $47.3 \%$ of the population of Ghana. They comprise the Bono, Asante, Adanse, Twifo, Asen, Fante, Akuapem, Akyem, Akwamu, Kwahu, Sehwi, Awowin, Nzima and Ahanta (Buah, 1998, p. 8). The name Akan, according to Danquah (1968, p. 198), means 'foremost, genuine' (from kan, first,) and is the corrupted form of Akane or Akana, corrupted by the early Arabs of the Sudan in Ghana and the early Europeans who visited the coast of West Africa in Guinea. The best known representatives of the Akan race are the Ashanti, Fanti, Akim, Akuapim, Assin and several of the present Twi-speaking races of the Gold Coast (Danquah, 1968). Akans have a rich variety of dialects which are related and shared in various degrees of vocabulary and other linguistic elements. These dialects which are mutually intelligible include Asante, Akuapen, Akwamu, Fante, Akyem, Agona, Assin, Denkyira, Twifo, Wassaw, Kwahu, Bron and Buem (Agyekum 2006, p. 206).

The Hair styling techniques of Akan women in Ghana traditionally has been; Natural hair styling, chemical relaxed heat style, Braids and twist, and weaves. According to Roseborough and McMichael (2009), natural hair style refers to hair of Sub-Saharan African origin in its original state, without any chemical product applied to permanently alter the pattern of the hair. Dansinkran hair style is typical example of Akan natural scalp hair style. Relaxed hair is the result of the application of a chemical compound to the natural hair to permanently break hydrogen disulfide bonds along the hair shaft (Roseborough \& McMichael, 2009; Miranda-Vilela et al., 2013). Heat style is the used of heated tools to change the hair characteristics (Roseborough \& McMichael, 2009). The effect of heat is however temporary and the style is lost when the hair comes into contact with water (Roseborough \& McMichael, 2009).

Braids are a hairstyle type that consists of sections of hair where segments (three) of each section are repeatedly twisted over each other to their very ends (Hughes, 2002). In 'cornrow' (a type of braids), the hair is braided onto the scalp in rows, usually all the way down to the nape of the neck, from where it then hangs (Samuels, 1995).

Twists, on the other hand consist of two segments of hair repeatedly twisted over each other to the very ends (Hughes, 2002).During the 1950s, hairstyles served as an important component of Kwame Nkrumah's programs to showcase "African personality" as ethnic, national, regional and pan-African. Hairstyles and turbans contributed in portraying the wearers' political affiliation. From the $1950 \mathrm{~s}$, hairdressing was one of the icons with 
which Nkrumah negotiated for the political liberalization of the Gold Coast colony. Nkrumah and his followers projected him as the folk heroes and epic heroes in Africa's past. He demonstrated "African pride" through anticolonial movements that yielded a peaceful transition to democratic rule. One of the ceremonial dresses of the leader, President Nkrumah was a simple hairstyle and the kente cloth of the renowned Asante, a visual icon of "African pride."

\subsection{Dansinkran Hairstyle Of Akan Queen Mothers}

Tharps and Byrd (2001) hypothesized that, "In the early fifteenth century, hair served as a carrier of message in most west Africa societies" they further discussed that, hairstyle could also be used for identification as well as communication of one's status, for example age, marital status, ethnic identity, religion, wealth and rank in the community. Akans of Ghana is no exception. Appiah prince (2017) post on my joy online 'Dansikran' was originally dancing crown which history explains was given by the Europeans coined from English words, 'dancing crown'. The haircut was the preserve of Queens and queen mothers in the Asante Kingdom. Traditional barber busily gives dansinkran haircut with Pairs of scissors to trim the patron's hair round the base of the skull. It leaves a shape of a round cylindrical crown or bowl on the head.

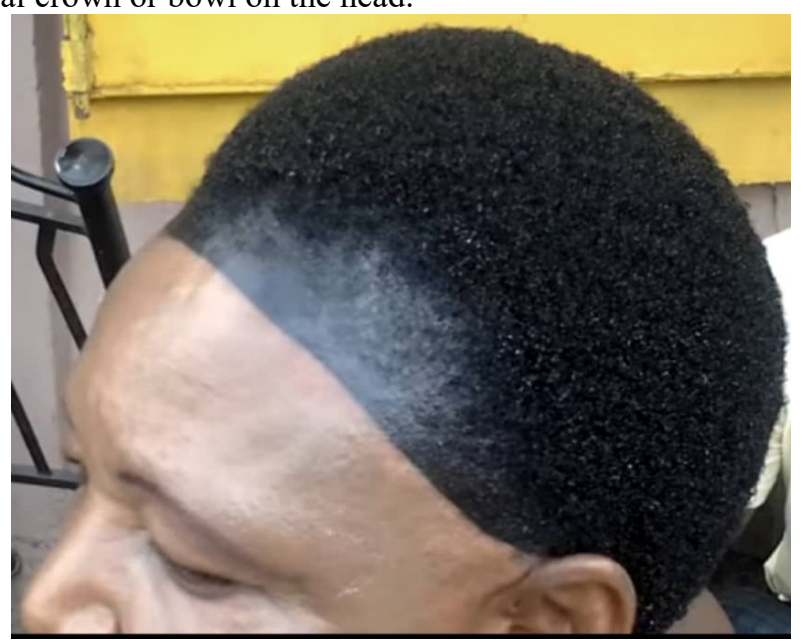

Source: Field Data, 2018

A black powdered charcoal-like substance is smeared on the hair to hold it firm. A little oil is applied to keep it soft before perfume spray gives it nice and pleasant fragrance. This is called 'dansikran'. It goes with carefully shaped eye-brow to match it.

At funerals and other cultural gatherings, queen-mothers, especially, spot this traditional hairdo to give them a unique look. The recent burial of the late Asantehemaa, Nana Afia Kobi Serwaa Ampem the second on (Nov. 2017) saw a display of rich Asante and Ghanaian Culture. 'Dansinkran' was very prominent during the late Asantehemaa's one week and burial rites. The story was no different during the $80^{\text {th }}$ day rites at which a successor was named.

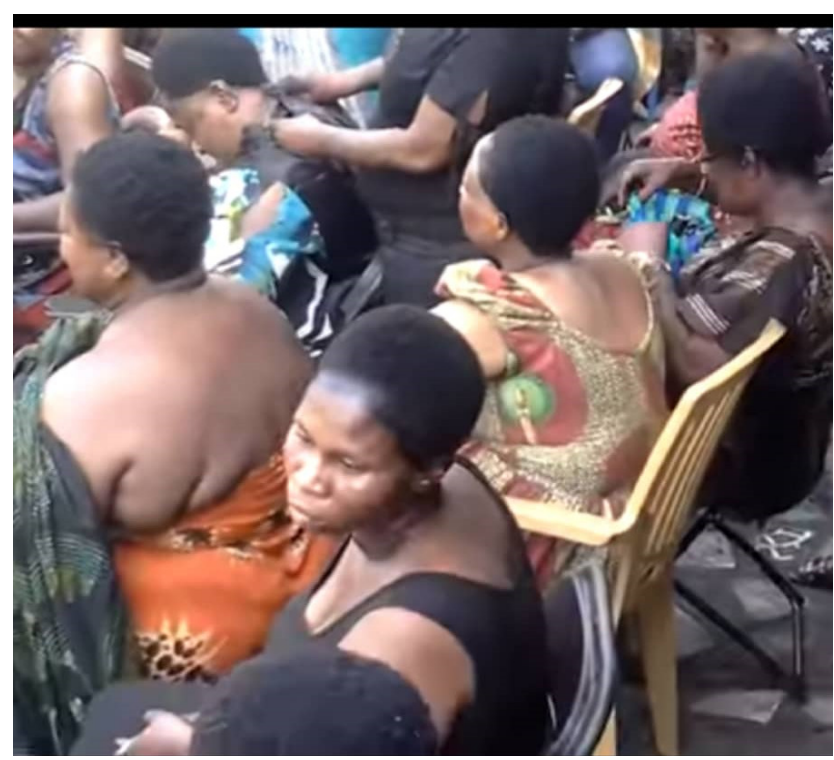

Source: Field Data 2018 
According to Rattray (1959) By the 1920s, Asante queen mothers were recognized for their dansinkran short, round and black haircut that tapers at their hairline. It is alleged, however, that during the nineteenth century, an Englishman who saw young Ohemea Yaa Asantewa of Ejisu dancing referred to her as the "dancing crown. Probably, he thought of her status as similar to his crowned Queen Victoria and her hairstyle that could represent an Ohemea's crown as the "dancing crown." One of the difficulties in imagining how the current dansinkran could describe a "crown" and contribute in visualizing the hairstyle that Ohemea Yaa Asantewa wore when dancing is that the visual, oral and written histories discuss the feat of an older Yaa Asantewa who was sporting a low hairstyle and purposefully defending the Asante state. Yet, this finding that Asante queen mothers had variations in hairdressings, even spectacular ones, similar to Sarpong's explanation about the significance of the nubile Asante girl's hairdressing, supports the view that the cutting of hair in culturally aesthetic designs, sometimes in the form of tufts, may have the oldest history among Asante people. Indeed, the representations of hairdressing in Rattray's set of carvings indicate that an Asante queen mother's hair used to be intricately designed. As Rattray describes, the "hair (visible only from the back) is cut in the fashion known as atiko pua; this coiffure is only permitted for Queen Mothers, princesses... and the king's wives." The carver distinguished the queen mother's head with her hairstyle and presented ornaments for other parts of her body. She wore beads around her neck, silver bangles on her wrist; beaded garters below each knee and toma beads around her waist.

\subsection{METHODOLOGY}

For this study, the researchers used a personal interviews with some Akan Queen mothers on their Dansinkran hair styles and utilized qualitative research methods, with heavy emphasis on literature review. The researcher employed a case study design in the research. Case study is an ideal methodology when a holistic, in-depth investigation is needed (Feagin, 1991). Case studies are designed to bring out the details from the viewpoint of the participants by using multiple sources of data. Researchers conducted semi-structured interviews in some selected palaces in Ashanti, Bono and Bono east, on Dansinkrna hair style with unique beauticians and on the reasons some women would like to have their hair styled in traditional Dansinkran style. The study target population was 10 Queen mothers from Ashanti, Brono-Ahafo currently Ahafo, Bono and Bono east regions. A sample size of 5 was chosen for the study. Purposive sampling technique was used to collect views of the Queen mothers. The data shows the Queen mothers interviewees' ages ranging fifty-two (52years), fifty five (55 years), Forty-two (42 years), seventy-four (74 years), and the elderly (98 years) respectively.

\section{Results and Presentations \\ 4.0 Introduction}

The chapter four focuses on the presentation of data obtained from semi-structured interview schedules. The study sought to "examine the socio-cultural significance of Dansinkran in Akan traditional setting".

\subsection{The Interview Findings.}

The interviewee 1, A Ninety-eight years old Queen mother posit that, "Queen wears dansinkran as an identity. In the olden days, during our time if you are a queen and you don't wear the dansinkran hair cut then you are not a queen. When you wear the dansinkran and you dress out everyone recognises you as a queen. Other people also wear the hair cut but theirs is different from ours (verbatim). That of the queen ${ }^{\text {ee }}$ is different since she works on it every day. Dansinkran is a whole dressing style. They wear a cloth down and wear another one on top like the way the Akan males wear their cloth, so when they are coming you see straight a way that a queen is coming. They dress in dansinkran style even how they wear their cloths and their footwear. When I was not wearing the dansinkran hair style, I used to dress in slit and ," ${ }^{c k a b a}{ }^{\text {ece }}$ like other Akan women but when you are a queen or a royal, you wear the dansinkran haircut and the dansinkran dressing style. It is done with six yards cloths down and six yards up worn like the style of the males. We don ${ }^{e t}$ use any drug on the hair, we use charcoal, the smoke dust on the cooking pot or fire lamp and shear butter, even if I tell you my age you won ${ }^{\text {ee }}$ believe it. I am 98 years but am still remember all these things. During our days, there was nothing like hair cream to retouch out hair but these days' ladies use creams and driers on their hair. The dansinkran hair style is originally for the royals. It cost much to do the dansinkran dressing because we use 12 yards of cloths to do it, six down, six up, so it was the royals who could afford. It was not for slaves. Dansinkran means „ $\Xi \mathrm{dZ}$ (to get satisfaction) for when you want to feel pampered. Those who are not royals do not wear sandals when they dress in the dansinkran dressing". 


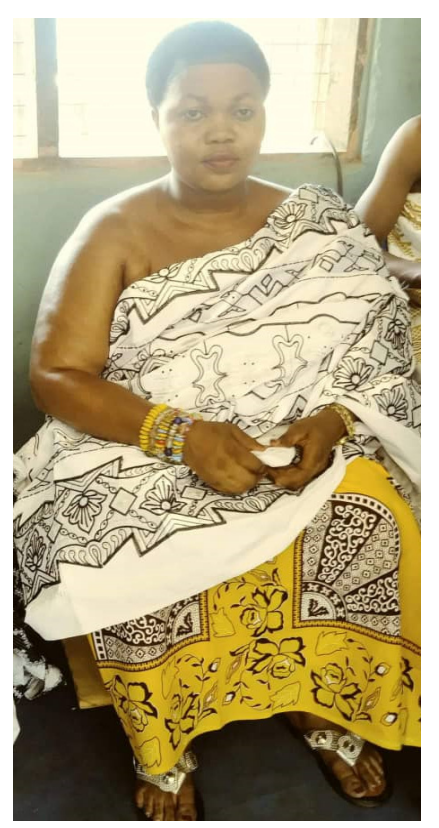

Source: Field Data 2019

This is in line with Appia (2017), who posit that, A black powdered charcoal-like substance is smeared on the hair to hold it firm. The interviewee put forward that, dansinkran hair style enhances thinking capacity of the Queen mothers as they used charcoal, it detoxify every chemical in hair and allow the brain to function with its full capacity. DeGruy (2000) postulated the consequence Africans have had as a result of long history of using drastic measures to attain "desirable" hair. Straightening highly textured African hair often requires the use of toxic chemicals or heat intensive tools such as a straightening comb or flat iron, which may be heated to over 400 degrees. Hair relaxers are used by millions of Black women and expose them to various chemicals through scalp lesions and burns . In addition, harmful chemicals cause minor to severe hair loss including balding, burns, and color change .

DeGruy (2000) noted that chemicals used in hair relaxers caused injury in the mouth and esophagus when ingested and such products must therefore be labeled poisonous. Tharps and Byrd (2001) postulated that, hairstyle could also be used for identification as well as communication of one"s status, for example age, marital status, ethnic identity, religion, wealth and rank in the community.

The interviewee 3 also put forward that, ; When you wear the "Dansinkran haircut and you even do not wear ring everybody recognises that you are a queen because that hair style identifies you more than the rings and other things since many people nowadays use the rings and the other things. I have now come to know that the hair style is called dansinkran and when you wear it you don"t have to wear ear rings and that you wear it to distinguish you from all others. When the queen wears slit and kaba with hair gear then she can wear the ear rings but when she dresses like a queen, and also do the dansinkran hair style then she cannot wear ear ring. The Interviewee; reiterated that, Akan traditional areas especially the Ashantie"s and we the Bono"s that is what we do, I don"t know what happens elsewhere.

Among the Akans for instance, we went to a (meeting) 'treaty' in Accra and you couldn't see the queens from Techiman (Brong Ahafo) and the Asantes but some of the queens from Accra and other areas also had the dansinkran, a lot of the queens wear that hair style it is not only seen in our area. Yes! as for the "'Dansinkran" even when a king dies you have to shave your hair nicely before you go and look at the body, if you have not shaved they won't allow you to go. So if you check you will see that when a king dies even ordinary women wear net on their hair and tie a red band on it. We the queen we shave our hair, if you wear hair gear they won"t allow you to go there. The above discussions is in line with Rattray (1959) who put forward in 1920s that, Asante queen mothers were recognized for their dansinkran short, round and black haircut that tapers at their hairline.

According to the interviewee 5, in the olden days the royal ladies do cut their hair style in Dansinkran style and dress accordingly to befit their status because they are elderly in the society. The Dansinkran scalp hairdo has remained unchanged as a means to preserve our culture. Dansinkran hair style and dressing denote elderly in the royal families of the Akan. Yes I have been a Baber for Ashanti queen mother for several decades. When kings or queens or any elderly from the royal families pass on, it is a custom for all the queen mother to dress and have their hair cut in Dansinkran style to serve as their homage to their late queen or kings. It is an identity to royalties. If you don"t want to plait your hair again then you have your hair cut in Dansinkran hair style to denote you are now elderly in the society. Queen mothers normally shave their hair in Dansinkran style to distinguish themselves from the commoners or from servant. Dansinkran can also signify that, our queen mother has passed away and we 
are showing our respect. Even if you are wearing hair gear you have to put it off and have your hair cut in Dansinkran style before you will be allowed to file pass the body. It is not a taboo for young ones to have Dansinkran hair cut if they wish. It is social class status in the society. Roseborough and McMicheal (2009) posit that, women commit considerable time and expense to daily hair grooming, both at home and the hair salons, for special occasions and everyday appearances. This tradition of women could be explainable by the fact that beautiful and healthy scalp hair generally expresses femininity irrespective of culture of the individual (Aboagye, 2011). The value of hair to women seems to be succinctly expressed in the words of Martin Luther that „hair is the richest ornament of women ${ }^{\text {ee }}$. For many women of African descent, hair is emotive, symbolic and an inseparable part of their identity.

\section{SUMMARY OF FINDINGS, CONCLUSION AND RECOMMENDATIONS 5.0 Introduction}

This chapter consists of the summary of findings, conclusions and recommendations.

\subsection{Summary of Findings}

The main focus of the study was to examine the socio-cultural significance of Dansinkran in Akan traditional setting. In the study, the following were unravelled; Dansinkran hair style and dressing were used to preserve and conserve cultural heritage. It is also used as identification in the Akan traditional setting. The chemicals used for Dansinkran hairdo was traditionally, also served as retentivity medicine. Dansinkran is a whole dressing style. They wear a cloth down and wear another one on top. like the way the Akan males wear their cloth,

\subsection{Conclusions}

To help the present and future generations come to terms with their true identity, every effort ought to be made to preserve and conserve Dansinkran. The study discovered the following.

* DAnsinkran hair style and dressing serve as royal identity.

* Dansinkran hair style enhances thinking capacity of the Queen mothers as they used charcoal, it detoxify every chemical in the hair and allow the brain to function with its full capacity.

* The study put forward that, Dansinkran hair style communicates one's statues, ethnic identity and rank in the community.

* Dansinkran hairdo has remained unchanged as a means to preserve culture.

* The study brought out that, Dansinkran hair style and dressing denotes elderly in the royal families in the Akans.

\subsection{Recommendations.}

The researcher recommends that in writing of our country history as a means to preserve and conserve it, the inclusion of history of hairdressing would make it richer and also add to the existing repository of knowledge.

\section{References}

Aboagye, B. (2011). Microscopy of chest and selected facial hairs in Ghanaian

Agyekum, K., (2006) „The sociolinguistic of Akan personal names ${ }^{\text {ee }}$ Nordic Journal of African Studies 15(2), 206-236.

Bell, Getting Hair "Fixed": Black Power, Transvaluation, and Hair Politics, (2008)1.

Bell, Monita.( 2008). "Getting Hair "Fixed": Black Power, Transvaluation, and Hair Politics." Thesis. Auburn University, Print.

Bolduc, C. \& Shapiro, J. (2001). Hair care products: Waving, straightening,

Buah, F.K., (1998), A history of Ghana, rev. edn., Macmillan, Oxford.

Byrd, A. D., \& Lori L. T. (2001). Hair Story: Untangling the Roots of Black Hair in America. New York: St. Martin's, Print.

Byrd, A. D., and Lori L. T. (200). Hair Story: Untangling the Roots of Black Hair in America. New York: St. Martin's,. Print.

Paulette. P. (1991) . Hair Piece: Perspectives on the Intersection of Race and Gender, 365. conditioning and coloring. Clinics in Dermatology, 19(4), 431-436.

Danquah, J.B., (1968), The Akan doctrine of God: A fragment of Gold Coast ethics and religion, Frank Cass \& Co. Ltd., London.

https://kwekudee-tripdownmemorylane.blogspot.com/2012/09/hairstyles-in-african-culture.html

https://www.commisceo-global.com/country-guides/ghana-guide

Hughes, Z. (2002). The explosion of braids and twists. Ebony, September 1 (pp. 108-111). in Aging, 1(2), 121129.

Johnson, T.A. \& Bankhead, T. (2014) Hair It Is: Examining the Experiences of Black Women with 
Natural Hair. Open Journal of Social Sciences, 2, 86-100. http://dx.doi.org/10.4236/jss.2014.21010 males. (Unpublished masters thesis). University of Ghana, Legon.

Mercer, K. (1987). Black hair/style politics. New Formations, 3, 33-54.

Mercer, Kobena. "Black Hair/Style Politics." New Formations 3 (1987): 33-53. Print.

Miranda-Vilela, A. L., Botelho, A. J. \& Muehlmann, L. A. (2013). An overview of chemical straightening of human hair: Technical aspects, potential risks to hair fibre and health and legal issues. International Journal of Cosmetic

National Women's Law Center and Law Students for Reproductive Justice(2010). If You Really Care About Environmental Justice, You Should Care about Reproductive Justice.

Oziogu, O.(2012) Blue Print Newspaper. World Press Thermsixth HTML. Retrieved March 2018 Pp50-52

Puke, T., Shaibu, M. (2001) Fundamentals of Citizenship Education. Lokoja. Shola Medupin Printers \& Publishers,Pp56-58.

Rattray, Religion and Art in Ashanti (1959), 66.

Rattray, R. S. (1930). Akan-Ashanti Folktales (Oxford: Clarendon Press,

Rattray, R. S. (1959). Ashanti (Oxford: Oxford University Press,

Rattray, R.S. (1927). Religion and Art in Asante, Oxford: The Clarendon Press,

Roseborough, I. E. \& McMichael, A. J. (2009). Hair care practices in African-American patients. Seminars in Cutaneous Medicine \& Surgery, 28,103-108.

Rosemary, G. (1964), Art: Mistress and Servant of Man and his Culture In the Study of Education and Art Pp3052.

Adams., B.R \& Gillette. C. K (1978) the Man and His Wonderful Shaving Device, 1st ed. Boston: Little, Brown, , 6-7.

Russell-Cole, Wilson, \& Hall, (2013) 26-53. "The Global Rise of Colorism." The Color Complex: The Politics of Skin Color in a New Millennium.

Sarpong, P. (1974). Ghana in Retrospect: Some aspects of Ghanaian Culture (Tema: Ghana Publishing Corporation, Sarpong, P. (1977). Girls ${ }^{e c}$ Nubility Rites in Ashanti Tema: Ghana Publishing Corporation.

Senghor, S. Black Culture, Festac " 77 handbook, African Journal Ltd. London, and the international Festival Committee, Lagos.1977,Pp80-82.

Sherrow, Victoria. Encyclopedia of Hair : A Cultural History. Westport, Conn.: Greenwood Press, 2006, http://www.loc.gov/catdir/toc/ecip0516/2005020995.html.

Trüeb, R. M. (2006). Pharmacologic interventions in aging hair. Clinical Interventions

Weitz, Rose. Rapunzele's Daughters: What Women "s Hair Tells Us about Women ses Lives. New York: Farrar, Straus and Giroux, 2004.

Weitz, R. (2001).Women, Power, and Hair, 